\title{
El Museu de les Aigües en el mundo MINECRAFT y otras visitas virtuales
}

\section{The Water Museum in the World of MINECRAFT and Other Virtual Visits}

\author{
Marta Soler Artiga, ${ }^{a}$ David Rovira Pujol ${ }^{\mathrm{b}}$ y Quim Garreta Escuder \\ ${ }^{\mathrm{a}}$ Museu de les Aigües msolerar@agbar.es ${ }^{\mathrm{b}}$ Museu de les Aigües david.rovira@agbar.es ${ }^{\mathrm{c}}$ Cubus Games \\ quim@cubusgames.com
}

\section{Resumen}

Adaptamos las visitas digitales a las necesidades y expectativas de cada público. Para público familiar recreamos el Museu de les Aigües en el mundo MINECRAFT con una finalidad divulgativa y educativa. A través de este videojuego creamos un reto y aprovechamos las ventajas de jugar y aprender desde un mundo imaginario: podemos equivocarnos sin una repercusión crítica para el entorno, viendo resultados más rápidamente que en la realidad, y con la opción de ser creativos y usar los recursos disponibles según nuestro criterio, posiblemente distinto a la solución propuesta por otros usuarios. El mundo de la fantasía nos permite licencias que en el museo no podrían darse y, al mismo tiempo, somos rigurosos con el contenido ofrecido. Así, a través del primer reto del Museu de les Aigües en MINECRAFT, proponemos a los participantes colaborar para afrontar los dos grandes desafios del planeta: el cambio climático y la pérdida de biodiversidad.

Para público adulto sugerimos una visita virtual $360^{\circ}$ que posibilite detenerse $y$ contemplar aquello que llame nuestra atención en el Museo de las Aguas. Mientras se realiza el recorrido por el museo, la guía comparte, en formato auditivo y textual, el contenido de la historia que nos narra. Seguimos su explicación y recorrido, pero, a diferencia de lo que sucedería en un vídeo, tenemos posibilidad de detenernos y girar 360 grados sobre nosotros mismos, de modo que podemos dedicar nuestra observación al aspecto que decidamos.

Para público familiar, optamos por crear una visita inmersiva al museo que permita realizar distintos recorridos según la temática de interés y conocer en profundidad aquellas piezas o módulos que más nos atraigan. Podemos pasearnos libremente por el museo, tal y como haríamos en una visita libre. Además, en esta visita incorporamos actividades complementarias más lúdicas y educativas que puedan realizar adultos y niños juntos. 
Por otro lado, con una finalidad tanto divulgativa como educativa, optamos por la realidad aumentada para incrementar la motivación y capacidad de entendimiento de jóvenes y adultos al mostrarles instalaciones industriales como la estación de tratamiento de agua potable. En este caso, si bien pueden desplazarse por la instalación siguiendo un recorrido guiado, también pueden detenerse en cada punto seleccionado y observar tanto lo que verían desde la instalación como el proceso que sucede bajo el agua o bajo el hormigón y que, en el caso de una visita tradicional, deberían imaginar...

Palabras clave: gamificación, MINECRAFT, realidad aumentada, visita virtual, aprendizaje basado en juegos

\section{Abstract}

We adapt online tours to meet the needs and expectations of each audience. For the family audience, we recreate the Water Museum in the world of MINECRAFT for outreach and educational purposes. Using this videogame, we create a challenge and use the advantages of playing and learning from within an imaginary world: we can make mistakes without critical repercussions for the environment and see results more quickly than in the real world, and with the option of being creative and using the available resources as we see fit, possibly in a different way to the solution proposed by other users. The fantasy world gives us license that would not be possible in the museum, and, at the same time, we are rigorous with the content provided. Thus, through the first challenge of the Water Museum in MINECRAFT, we offer participants the chance to work together to meet the two great challenges facing the planet: climate change and the loss of biodiversity.

For the adult audience, we suggest a $360^{\circ}$ virtual tour that makes it possible to stop and contemplate the things that catch our eye in the Water Museum. While taking a tour through the museum, the guide shares the content of the story they tell us in audio and text format. We follow their explanation and route but, unlike what would happen in a video, we can stop and turn $360^{\circ}$ on ourselves, so that we can observe any aspect we wish.

For the family audience, we decided to create an immersive tour of the museum, which makes it possible to take different tours depending on the topic of interest and to study the pieces or modules that we find most interesting. We can stroll freely through the museum, just as we would on an unguided visit. Furthermore, in this tour, we include more recreational and educational supplemental activities that adults and children can do together.

Also, for outreach and educational purposes, we have opted for augmented reality to increase the motivation and comprehension of young people and adults by

2021, Editorial Universitat Politècnica de València (cc)) BY-NC-ND 
showing them industrial facilities such as the drinking water treatment plant. In this case, while they can move through the facility following a guided tour, they can also stop at each chosen point and observe what they would be able to see from the facility and the process that is taking place underwater or under the concrete and which, in the case of a traditional tour, can only be imagined.

Keywords: gamification, MINECRAFT, augmented reality, virtual tour, game-based learning. 


\section{Introducción}

Un museo es un espacio de contenido; pocas instituciones se dedican pura y sencillamente a almacenar y ordenar información para luego presentarla en forma de relatos. Si bien hasta ahora la forma más habitual de descubrir todo este contenido ha sido pasear por sus salas y participar en sus actividades, los museos también son visitables online, y el coronavirus y su consecuente confinamiento han supuesto una ocasión para que instituciones como el Museu de les Aigüesaceleren su transformación digital y puedan explotar su contenido de forma virtual.

Al igual que en una visita presencial, en un entorno digital deben crearse experiencias intelectualmente satisfactorias, estimulantes y emocionales. Las tecnologías digitales proporcionan nuevas maneras de compartir historias y de invitar a la participación mediante un acceso abierto y transparente. Hay que tener presente que una transformación digital requiere un nuevo enfoque, nuevas ideas, nuevos productos, nuevos formatos y nuevas metodologías. Conocer muy bien el público al que el museo se está dirigiendo es fundamental para el éxito de la estrategia de digitalización. Es importante diversificar en diferentes formatos digitales y diferentes narrativas, según públicos y objetivos. La belleza de la modalidad online es que el contenido puede estar disponible en múltiples plataformas ya existentes para maximizar la difusión, de modo que sea más accesible a un público más amplio.

Poner al público en el centro y pensar en lógica digital han sido los motivos que nos han llevado a considerar necesaria la creación de varias visitas virtuales al Museo de las Aguas:

- Una visita familiar a través de la reproducción del museo en el mundo del videojuego MINECRAFT (https://www.youtube.com/watch?v=HrJ7YuVSYkU)

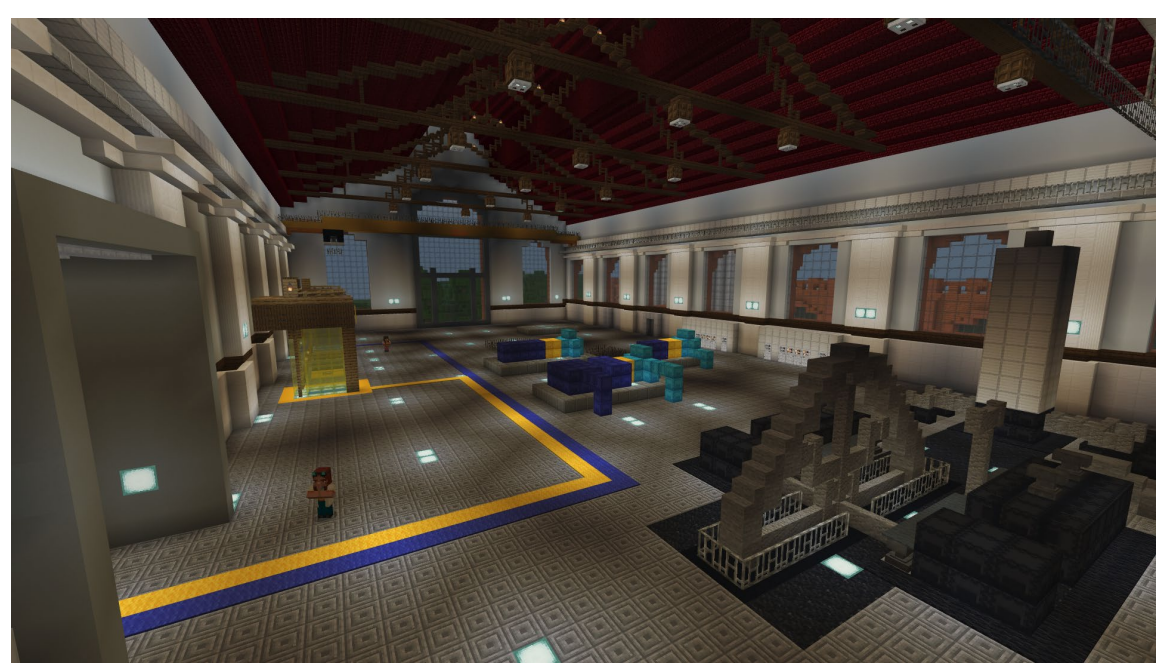

Fig. 1. EI Museu de les Aigües en MINECRAFT 
- Una visita general a través del formato inmersivo $360^{\circ}$ (https://www.youtube.com/watch?v=D0hrPvuP9YQ)

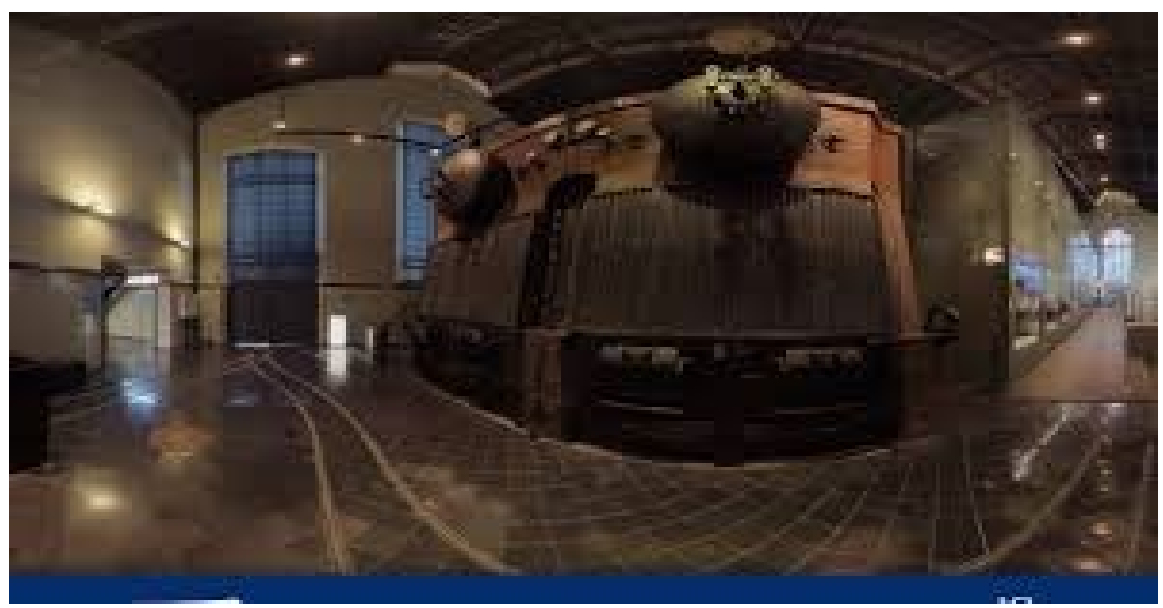

Fig. 2. El Museu de les Aigües en $360^{\circ}$

- Una visita educativa en realidad aumentada (https://www.youtube.com/watch?v=Xugz0XN1NVE)

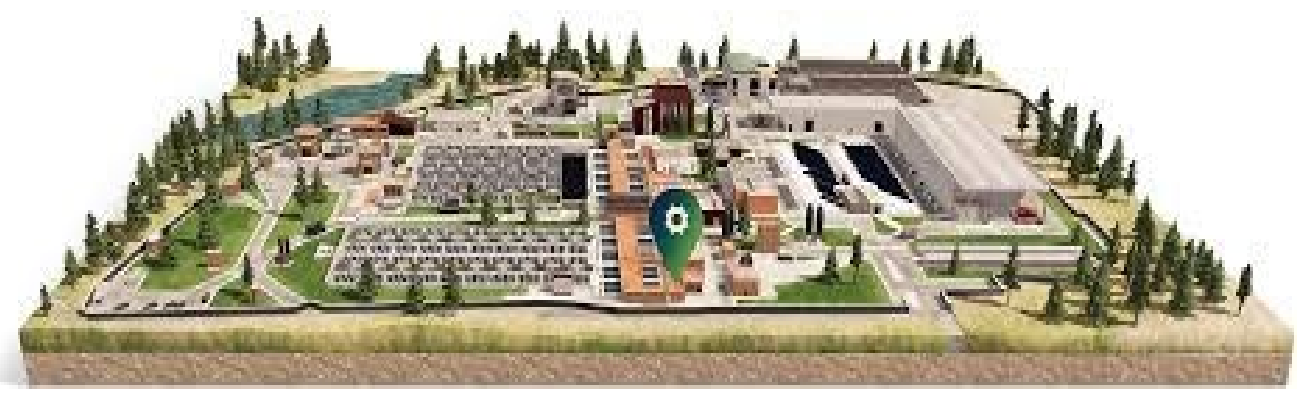

Fig. 3. La potabilizadora en realidad aumentada

- Una visita general a través del formato interactivo (https://www.fundacioagbar.org/es/inicio)

\subsection{Breve presentación de la institución}


Para comprender la innovación propuesta presentamos las características más relevantes de la institución donde se ha desarrollado.

El Museu de les Aigües es el instrumento principal de la Fundación Agbar para hacer efectivo su compromiso con la cultura y la educación. Es un espacio centrado en el conocimiento y los valores de la cultura del agua y en el patrimonio relacionado con ellos.

Es un equipamiento educativo y cultural de referencia, con un enorme valor histórico y artístico intrínseco de los edificios modernistas de la Central Cornellà que lo acogen. Se distingue también como agente muy activo, dinámico y en evolución continua, que apuesta cada vez más por nuevas formas de colaboración con el entorno para ir ensanchando el alcance de su impacto cultural, educativo y social.

La Central Cornellà de Aguas de Barcelona, construida en 1909, es una instalación que capta agua del acuífero del Llobregat y la impulsa a la red de distribución. Constituye un activo estratégico del sistema de abastecimiento del área metropolitana de Barcelona. Dentro de este espacio abrió el museo en 2004 con el proyecto educativo en torno al agua y la difusión del patrimonio como sus dos grandes pilares.

Durante sus 16 años de funcionamiento ha tenido en torno a 50.000 visitantes anuales, el 50\% de ellos escolares.

En 2019, el Museo se amplió con la apertura al público del jardín industrial de la Central Cornellà y la construcción de la cascada Gaudí. Se desarrolló asimismo un nuevo proyecto educativo con la experimentación y la participación como ejes principales y se consolidó la apuesta por atraer al público familiar, con la sostenibilidad como concepto vertebrador. Son unas líneas de trabajo alineadas con los objetivos de Aguas de Barcelona y unos cambios recogidos en el Plan Estratégico del Museu de les Aigües 2018-2023 y el Plan Director de la Fundación Agbar 2017-2020.

Con la crisis sanitaria ocasionada por el coronavirus se plantea la necesidad de establecer una nueva estrategia condicionada por el cierre temporal del Museu de les Aigües para preservar el buen funcionamiento de una planta estratégica para el servicio de abastecimiento de agua como es la Central Cornellà. El escenario de actuación exclusivamente digital se prolongará, muy probablemente, más allá de 2021. Cuando el museo reabra apostará por un modelo híbrido, en el que el proyecto digital siga teniendo sentido. 


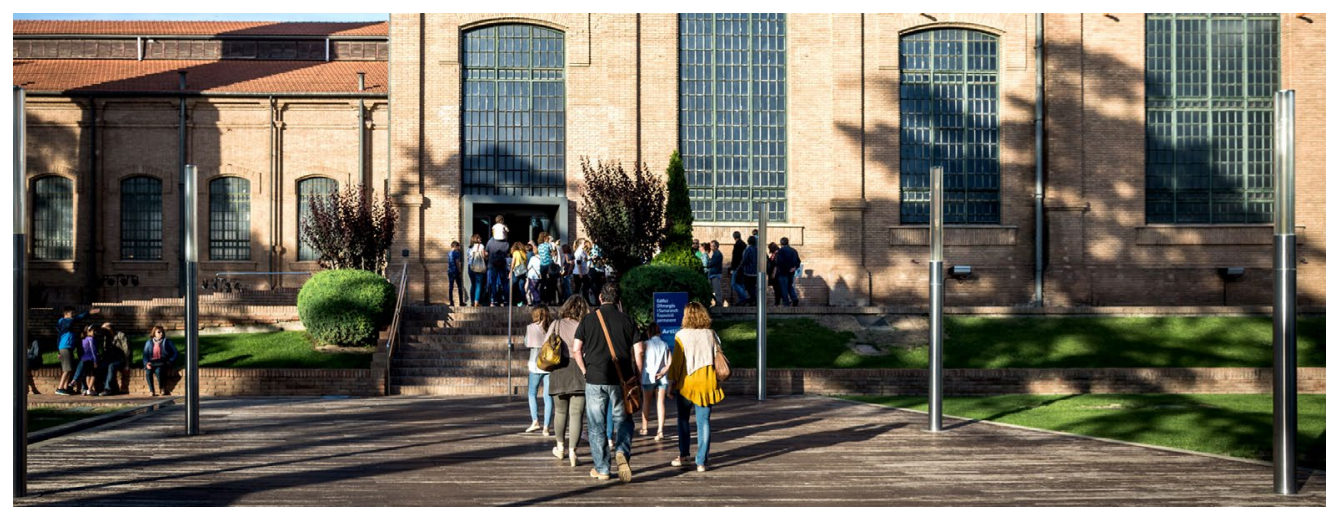

Fig. 4. El Museu de les Aigües

\section{Objetivos}

El uso de tecnologías crea nuevas conversaciones con el público que por algún motivo no puede acceder físicamente al Museo. Así, el uso de tecnologías inmersivas, por ejemplo, posibilita el desarrollo de visitas virtuales más atractivas, más reales e innovadoras y, a menudo, mucho más interactivas que en un entorno físico. Precisamente, mantener conversaciones activas con el público permite entender el tipo de contenido que esta demanda. En este sentido, el valor debe ponerse en el usuario y no tanto en las instituciones. $\mathrm{Y}$, sobre todo, si entendemos que el formato de las visitas guiadas necesita ser revisado y actualizado en los museos, debemos aprovechar la creación de las visitas virtuales para resolver las principales dificultades que se dan en la interacción, atracción y comprensión de una visita guiada. Así, el contenido a desarrollar ha de permitir interactuar con los visitantes tanto online como in situ cuando el Museo vuelva a abrir sus puertas.

En este museo tenemos como misión transformar nuestro entorno más cercano, día a día, a través de la educación y el conocimiento, para generar una gran ola que impulse la evolución de nuestra sociedad hacia un mundo más sostenible y sensible al agua, provocando nuevas miradas y generando conversaciones reales alrededor del agua para crear una nueva experiencia hacia una conciencia global más conocedora y sabia sobre este recurso que nos da vida y sentido.

Por todo ello, nos proponemos como objetivo estratégico:

- Reinventar la manera de disfrutar del Museu de les Aigües mediante la digitalización de la experiencia del visitante, recuperando así el contacto con él de una manera vanguardista.

Los objetivos operativos que deben permitir conseguirlo incluyen: 
- Utilizar tecnologías inmersivas para desarrollar visitas virtuales más atractivas e interactivas, adaptadas a la forma en que cada persona se interesa por el museo.

No queremos proponer visitas principalmente estáticas, sino activas, dinámicas e interactivas.

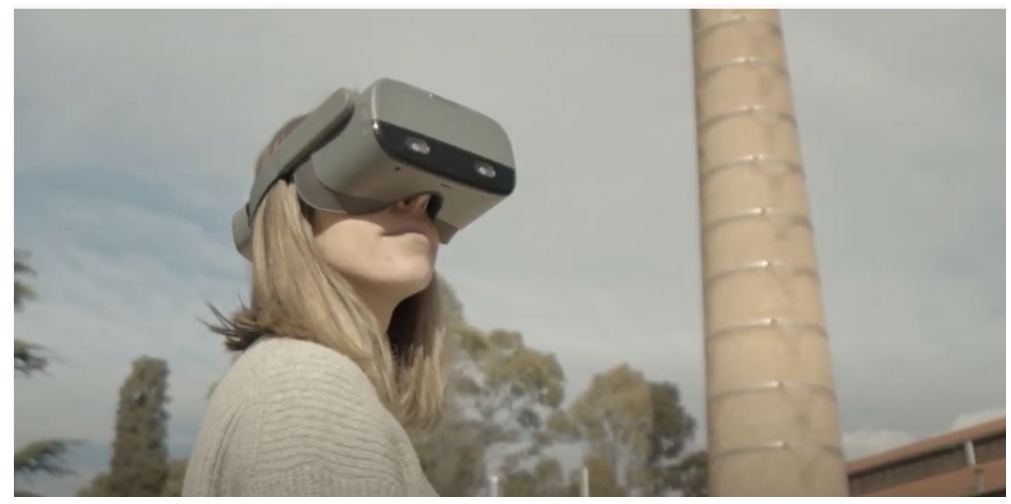

Fig. 5. Visita virtual con gafas de realidad virtual

\section{Desarrollo de la innovación}

\subsection{Análisis del contexto: públicos y visitas al museo}

Paralelamente a la realización del análisis DAFO de la institución en el medio digital, observamos cuáles son las necesidades de los públicos a quienes nos dirigimos. Destacamos que:

- El público educativo acelera su transformación digital con la consecuente demanda de recursos educativos digitales que permitan trabajar al profesorado y al alumnado desde casa.

- El público familiar incrementa la demanda de actividades de ocio con contenido educativo para el entretenimiento familiar debido a la limitación de opciones culturales y con la motivación de realizar actividades conjuntas.

- El público adulto incrementa el consumo de actividades culturales y de ocio en formato virtual.

- Las personas mayores rompen la brecha digital y ponen de manifiesto la falta de opciones de ocio y educación para este colectivo.

Consideramos que el gran cambio en las instituciones culturales tiene lugar en el tráfico que va desde la perspectiva corporativa hasta centrarse en el usuario, el cliente, el visitante, el 
espectador, el lector. Los nuevos hábitos de consumo cultural, las nuevas expectativas de los usuarios, una audiencia más participativa, todo ello requiere una diversidad de ofertas y diferentes niveles de información y contenidos diseñados para distintos públicos. La atención se centra cada vez más en el valor de la experiencia. Poner al usuario en el centro conlleva cambios organizacionales y la necesidad de colaboración transdepartamental. Las estrategias y las herramientas integradas a través de diferentes canales físicos y digitales son clave para proporcionar una experiencia contextual rica, consistente y personalizada.

El concepto de experiencia de usuario (user experience, UX) es más amplio de lo que en principio suele considerarse. La UX no debe entenderse solo como la experiencia en Internet, en diseño y navegación de webs o de aplicaciones móviles, y no se produce únicamente en el entorno digital. La UX comprende todo lo que el usuario percibe y experimenta en el conjunto de su relación con una organización que ofrece servicio al público: lo abarca todo, lo presencial y lo digital, lo importante y los detalles menores. Y, más allá de unas siglas, estamos hablando de un ingrediente (o conjunto de ingredientes) que conforma algo importantísimo: la estética. La estética hace referencia no solo al aspecto visual, sino a todo aquello que las personas visitantes o usuarias van a percibir a través de sus sentidos durante la experiencia.

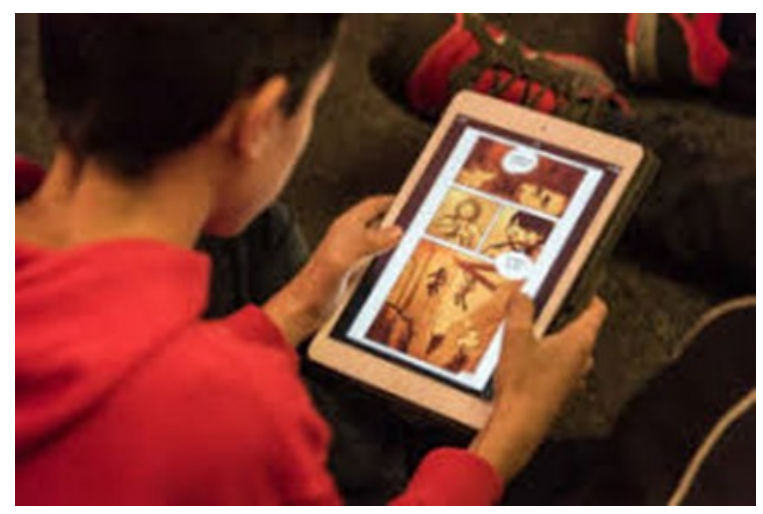

Fig. 6. Ejemplo de digitalización del Museu de les Aigües

\subsection{Visita propuesta para público familiar: MINECRAFT Education}

¿Cómo interesar a las familias en una visita virtual al museo? ¿Cómo continuar dando a conocer las peculiaridades de este espacio y el conocimiento generado en torno a la gestión del agua y la relación entre medio ambiente, personas y ciudad?

Basamos la respuesta en la gamificación y las soluciones basadas en los juegos, las técnicas que aumentan el atractivo de los procesos de aprendizaje, la creatividad, la productividad y la capacidad de retener conocimientos. 
Acostumbrados a pantallas, experiencias interactivas e información al alcance de sus dedos, las familias pueden sacar partido de la tecnología y aventurarse en iniciativas apasionantes en interacción con el museo virtual.

Para los museos resulta difícil desarrollar juegos y más aún que estos lleguen a una gran audiencia, por lo que nos parece mejor estrategia incluir nuestro patrimonio dentro de un juego que ya está online.

MINECRAFT ofrece contenido apasionante para participantes y familias e incluye actividades divertidas destinadas a despertar la imaginación y dar rienda suelta a la creatividad, por lo que creamos módulos educativos sobre el agua para MINECRAFT EDUCATION EDITION, una versión educativa de MINECRAFT diseñada específicamente para que resulte una herramienta muy intuitiva, tanto dentro de las aulas como en el tiempo de ocio, especialmente en el segmento de edad de entre 7-14 años. Los módulos están disponibles para su descarga y se dividen por temáticas. MINECRAFT EDUCATION EDITION ofrece una gran herramienta de exploración, creación, storytelling y aprendizaje digital, una herramienta del learning by doing sin precedentes. Profesores y familias de todo el mundo utilizan esta plataforma tanto para el aprendizaje en línea como presencial porque ofrece herramientas de colaboración a los estudiantes y así pueden trabajar conjuntamente para alcanzar diferentes retos. Niños, niñas y adolescentes también utilizan esta plataforma como divertimento, aprendiendo sin que ese sea el principal objetivo por el cual usan la plataforma.

El Museu de les Aigües estrenó una nueva actividad para el público familiar durante las Navidades de 2020: vivir una aventura virtual en el mundo de MINECRAFT, con la biodiversidad y la lucha contra el cambio climático como temática principal. De este modo, el museo prosigue su tarea de divulgación del conocimiento del agua y el respeto al medio ambiente, concienciando a la sociedad sobre la sostenibilidad a través de una clara apuesta por la transformación digital.

A través de este juego se propone a los usuarios colaborar para hacer frente a los dos grandes desafíos del planeta: el cambio climático y la pérdida de biodiversidad. Para ello, los jugadores deberán crear, dentro del mundo de MINECRAFT, acciones que permitan proteger la flora y la fauna del museo, consiguiendo que las especies autóctonas se reproduzcan y dando refugio y alimento a aquellas que están amenazadas.

El cambio climático y la pérdida de biodiversidad tienen consecuencias en el ciclo del agua y el bienestar de las personas y, precisamente por esto, el Museu de les Aigües propone una actividad a partir de la cual se podrá conocer qué es la biodiversidad y en qué nos beneficia, cuál es la relación entre el cambio climático, el agua y la pérdida de biodiversidad, y cómo se puede fomentar la renaturalización de espacios.

\subsection{Visita propuesta para público general adulto: visita virtual $360^{\circ}$}


La visita virtual inmersiva de $360^{\circ}$ muestra contenidos inéditos de localizaciones que normalmente los visitantes no pueden contemplar en su visita al museo. El vídeo está narrado por una persona que guía al visitante virtualmente por todo el museo para crear mayor engagement. Se muestran los espacios más emblemáticos del museo (los pozos, las calderas, los generadores, el circuito de vapor del sótano, el depósito, la sala de máquinas, la cascada Gaudí...) así como instalaciones a las que el público, como ya se ha indicado, no tiene acceso en una visita normal. El uso de nuevas tecnologías ofrece la oportunidad de compartir espacios a los que el público general no puede acceder, entre otros motivos, por razones de aforo o seguridad, por lo que resultan especialmente interesantes para compartirlos en formato digital online. El Museu de les Aigües cuenta con localizaciones, como la galería de tuberías, de gran valor divulgativo en el campo de la ingeniería, que se ofrecen mediante cápsulas informativas que también representan una gran oportunidad para compartir curiosidades o historias que normalmente se pasan por alto en las visitas guiadas. La realidad virtual da a esta visita un carácter inmersivo potente, situando a las personas dentro de los diferentes espacios con una visión totalmente distinta a la que tendrían en una visita física al museo.

\subsection{Visita propuesta para público general: visita virtual interactiva}

Las personas visitantes pueden recorrer el Museu de les Aigües a través de una plataforma web intuitiva e interactiva. Mediante un plano, el usuario puede visitar, con muy alta calidad gracias a la tecnología de la gigafoto, las diferentes localizaciones que componen el museo. La visita consta de vídeos y fotografías $360^{\circ}$, así como otros elementos multimedia como efectos de sonido y vídeo, narración, imágenes, texto y minicápsulas de vídeos explicativos para dar información detallada al visitante sobre algunos elementos. Todo ello facilita el viaje temporal al pasado de una central con un largo recorrido histórico y permite poner en valor materiales del archivo histórico. Desde la visita interactiva se tiene acceso, a través de enlaces, a las adaptaciones online de los juegos en las que ya se está trabajando.

\subsection{Visita propuesta para público educativo: visita en realidad aumentada}

Su vocación de dar a conocer el patrimonio de Aguas de Barcelona -así como generar conocimiento y conciencia ambiental en torno al agua- ha llevado al Museu de les Aigües a habilitar una app que permite realizar un recorrido virtual y en realidad aumentada por la planta potabilizadora de Sant Joan Despí, una infraestructura clave para abastecer de agua al área metropolitana de Barcelona y una de las más avanzadas tecnológicamente de Europa. La aplicación, que combina imágenes de gran realismo con información interactiva sobre el espacio y los procesos que en él se desarrollan, quiere convertirse en un recurso didáctico de gran utilidad para profesorado y alumnado de secundaria, que se puede complementar con la 
guía y el catálogo de actividades educativas disponibles. La app se puede descargar gratuitamente en Google Play y Apple Store.

Desde que se creó en 1955 hasta hoy, la estación de tratamiento de agua potable (ETAP) de Sant Joan Despí se ha convertido en una de las plantas potabilizadoras tecnológicamente más avanzadas de Europa. En ella, los procesos clásicos, como el pretratamiento, la clarificación y la desinfección final del agua, conviven con otros de última generación, como el tratamiento del agua con ozono y carbón activo, la ósmosis inversa y la reutilización de residuos.

La realidad aumentada (RA) es una proyección de objetos en 3D a través de la cámara del móvil o de una pantalla táctil. Una aplicación de RA permite generar una experiencia inmersiva en la que se puede tener la sensación de estar viendo un objeto real.

Esta aplicación permite visualizar una maqueta en 3D y a escala real de la planta potabilizadora de Sant Joan Despí de Aguas de Barcelona y explorar los diferentes procesos por los que pasa el agua para ser potabilizada. Es una visita virtual que casi parece una visita real...

Hemos creado dos modalidades de visita posibles: la visita divulgativa, enfocada al público escolar y al público general interesado en conocer cómo se produce agua potable, y la visita técnica, dirigida al público que desea conocer los detalles más técnicos del proceso de potabilización.

El primer paso en una experiencia de RA es posicionar el modelo, en este caso el modelo a escala real de la ETAP. Se busca una superficie plana como una mesa o un espacio en el suelo suficientemente grande para colocar el objeto; la maqueta se puede hacer más o menos grande; el modelo de la ETAP se puede mover a la posición que se quiera; solo hay que clicar sobre el objeto y desplazarlo. También se puede hacer más grande o más pequeño deslizando los dedos. Cuando el modelo está en el lugar que se desea y al tamaño que se quiere, se empieza. Pulsando sobre el botón, el modelo queda fijado y la visita virtual se inicia. Además de navegar por las secciones, también se puede pasear por el modelo, acercándose y descubriendo detalles interesantes que de lejos no se pueden ver. Acercándose más, puede verse que toda la instalación virtual es una réplica de la real.

La navegación por la visita virtual se realiza secuencialmente, pulsando sobre los marcadores. Una narración presenta y acompaña la visita, de modo que el visitante tan solo tiene que ir siguiendo los marcadores para ir accediendo a los diferentes procesos. Una vez se clica un marcador sobre la maqueta, se accede a una nueva vista donde se muestra, mediante un modelo 3D, el proceso que se lleva a cabo en ese edificio. Dentro de cada sección, hay que clicar sobre otro marcador para ver la animación correspondiente a cada proceso. En la visita virtual damos una explicación general de lo que se hace en cada proceso y proponemos cuestiones y preguntas que el profesor puede plantear con sus alumnos para profundizar en el conocimiento de cada uno de ellos. 


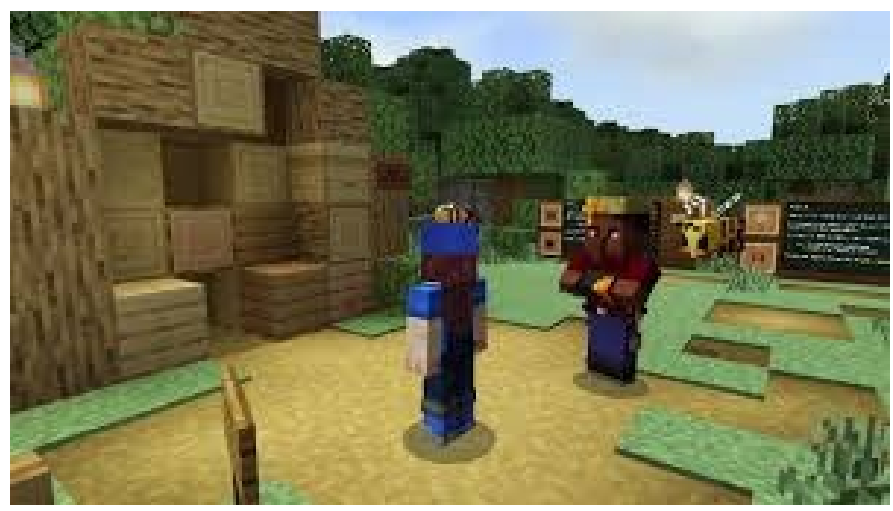

Fig. 7. Visita virtual en el Museu de les Aigües en Minecraft

\section{Resultados}

Sin duda, la virtualización de los recorridos y exposiciones del museo ha permitido extender el conocimiento de la colección y el patrimonio, dando visibilidad al mismo. Pero para evaluar si las visitas virtuales son una buena estrategia para alcanzar el objetivo del museo se han desarrollado indicadores clave de rendimiento (KPI según sus siglas en inglés) para cada una de las visitas:

- Análisis web (web museo y web visita virtual)

$\circ$ Sesiones

- Páginas por visita

- Duración de la sesión

- Objetivos de conversión

- Porcentaje de crecimiento de visitas

- Redes sociales
○ Número de seguidores
- Número de seguidores activos
- Visualizaciones
- Porcentaje de crecimiento
- Shares
- Engagement / compromiso (grado de fidelización)
- Reach / alcance (número de cuentas únicas expuestas a la publicación)
- Likes / reacciones / favoritos
- Comentarios / respuestas
- Menciones
- Viralidad
- Impacto hashtag

En relación a los KPI para esta presentación destacamos que: 
- El teaser de la visita MINECRAFT ha sido visto, en mes y medio, por más de 20.000 personas. Un $15 \%$ de estas han entrado en la web para acceder al recurso y un $15 \%$ han realizado la visita.

- El teaser de la visita $360^{\circ}$ ha sido visualizado, en mes y medio, por 150 personas. Sin embargo, ha habido una visualización directa del contenido por parte de más de 15.000 personas. En torno al $5 \%$ de los usuarios que empiezan la visita la finalizan.

- El teaser de la visita a la ETAP ha sido visualizado, en mes y medio, por casi 300 personas y se han realizado casi 1.000 sesiones en la app. Por lo tanto, el tráfico hacia la aplicación no ha procedido de la publicidad sino de otros canales. En este caso, en torno al $40 \%$ de los usuarios que empiezan la visita la finalizan.

El análisis de los KPI obtenidos por Google Play, junto con otras medidas más transversales como los focus group y las encuestas, permite saber que, en general:

- Es clave facilitar el acceso al recurso, evitando formularios y otros pasos intermedios.

- Se utiliza el servicio de oficina técnica para consultar el acceso y uso a las tres modalidades. Las preguntas más habituales son: ¿cómo jugar a MINECRAFT?, ¿qué son las gafas 3D y dónde se adquieren?, ¿cómo se instala la realidad aumentada?

- Se valora que la visita no reproduzca las que se realizaban in situ al museo, sino que ofrezca la opción de conocer otros lugares del mismo, realizar otras actividades en él o ver procesos que suceden en el interior de instalaciones.

- Finalmente, también se recuerda que digitalización no significa accesibilidad y que cada recurso es accesible solo en cierta medida.

Concretamente, sobre MINECRAFT se destaca:

- Promueve la creatividad, la colaboración y la resolución de problemas en un entorno divertido e imaginativo. Todo ello proporciona a las familias un incentivo más a la hora de aprender conceptos nuevos, al usarse un elemento lúdico e interactivo donde el usuario es el protagonista y donde sus acciones y toma de decisiones resultan relevantes, lo que hace que el aprendizaje sea algo más divertido, interesante y, sobre todo, efectivo.

- Al niño o niña se le despierta el interés por aprender a través de un juego que ya conoce y sabe lo divertido que puede llegar a ser. Las características del propio juego invitan a la exploración y la creatividad, por lo que es un entorno perfecto para que los estudiantes refuercen su independencia y vayan probando cosas mediante ensayo y error hasta conseguir lo que se han propuesto.

- Permite actividades individuales y en grupo donde se generan las interacciones más interesantes entre participantes. 
- La comunicación del proyecto es importante y funciona bien.

- $\quad$ El uso de MINECRAFT EDUCATION EDITION en su total potencia (y no solo para reproducir monumentos) genera interés en la comunidad educativa y museística.

- Se debe facilitar mucho más el acceso a la actividad reduciendo las posibles fricciones con las que pueden encontrarse los usuarios, surgidas de los pasos necesarios (descarga de aplicaciones, envío de correos electrónicos, generación de contraseñas...) que lleva implícitos el uso de una herramienta tan completa y potente como MINECRAFT EDUCATION EDITION.

Concretamente sobre la visita virtual $360^{\circ}$ :

- Son una minoría quienes usan las gafas 3D y tienen la experiencia completa.

- Se solicitan distintos niveles y estilos de locución.

Concretamente sobre la vista en realidad aumentada:

- En educación, una de las ventajas evidentes de la realidad aumentada es que amplía posibilidades y abre nuevas oportunidades para aprender en contextos distintos y experimentar perspectivas con objetos virtuales que de otra manera podrían ser muy difíciles de lograr.

- Pensar en experiencias de aprendizaje con este tipo de formatos requiere una planificación extra por parte de quienes enseñan.

- Hay teléfonos móviles sin acceso a esta aplicación.

- Facilita que aspectos visuales e interactivos convivan. Poder visualizar un elemento virtual en el mundo real implica que la aceptación y adquisición del nuevo conocimiento se mezcle con la experiencia de manipularlo tú mismo.

- La formación de los docentes en tecnología desempeña un papel fundamental.

- La realidad aumentada es una buena opción para aumentar la motivación los estudiantes.

- La realidad aumentada contribuye a la participación activa y hace que el aprendizaje sea más inmersivo.

Se confirma que las visitas virtuales son un recurso pedagógico al alcance de todos y todas, puesto que no requieren desplazamiento al lugar físico donde se sitúa un museo, sino que este se encuentra disponible en la red y en abierto. Las ventajas de una visita virtual a los museos citadas por los usuarios son:

- Se puede visitar asincrónicamente.

- No requiere desplazamiento al lugar físico.

- Se puede exponer y trabajar en el aula escolar.

- El contenido se puede visualizar y es posible profundizar en él puesto que no hay límite temporal en su contemplación. 
Todos estos hechos contribuyen a ampliar las fronteras educativas y posibilitan nuevos escenarios de actuación en el aula sin necesidad de disponer de ciertos recursos económicos que permitan el desplazamiento físico.

\section{Conclusiones}

Los resultados obtenidos nos permiten afirmar que:

- El contenido y las experiencias digitales deben servir para conectar con los visitantes y usuarios.

- Para alcanzar este objetivo es clave adecuar los canales y contenidos a las necesidades y expectativas de los usuarios.

- Para poder hacerlo debemos entender muy bien quién es el público objetivo y la segmentación por intereses del mismo para cada una de las acciones propuestas.

- El contenido creado debe aportar valor y servir para crear nuevos diálogos entre el museo y su público.

- Este contenido debe ser al mismo tiempo creativo, interactivo, divulgativo y despertar interés.

Basándonos en el análisis de los tres casos expuestos, y sin disponer de datos estadísticos exhaustivos del tráfico, vemos que estos formatos de visitas virtuales resultan de interés por parte del público. La clave del éxito, suponemos, se basa en unos buenos storytelling y engagement, que hacen que los asistentes sigan las visitas en su totalidad con mucho interés. Es un modelo que presenta nuevas oportunidades para las instituciones culturales, quedando por explorar la gran variedad de formatos en los que se pueden empaquetar este tipo de visitas. Imaginemos una visita virtual guiada por una persona famosa como, por ejemplo, un director de museo o un científico: en el chat se pueden organizar juegos de pistas, concursos y preparar sorpresas, y la visita virtual con guía se puede ofrecer como una experiencia digital gratuita que se puede adquirir y regalar a un amigo que vive en otra provincia o incluso en otro país...

Los buenos resultados obtenidos en los distintos formatos nos llevan a dar nuevos pasos para profundizar. Así, proponemos diferenciar nuevos ejes temáticos en cada propuesta:

- En la visita familiar, a través de la reproducción de nuevos retos en el mundo MINECRAFT, ahora más vinculados a los objetivos del desarrollo sostenible, a la gestión eficiente del ciclo del agua, a la vinculación entre agua, salud y bienestar.

- En la visita educativa en realidad aumentada, mediante nuevas propuestas complementarias de actividades de reflexión sobre la experiencia (nuevas guías didácticas, propuestas de experimentación, propuestas de metodología Tinkering).

- En la visita inmersiva, a través de la diferenciación de ejes temáticos: historia, patrimonio, ciencia, tecnología, sociedad, política, medio ambiente... 
Nos damos cuenta de que nos queda pendiente explorar el valor del directo en las distintas modalidades:

- En la visita familiar, a través de la reproducción del museo en el mundo del videojuego MINECRAFT: mediante sesiones guiadas y colaborativas en días señalados.

- Una visita general a través del formato $360^{\circ}$ : mediante visitas virtuales live con famosos por temáticas. El live streaming permite un nivel de interacción muy elevado, por lo que se utiliza mucho para crear y reforzar una comunidad.

- Una visita educativa en realidad aumentada mediante la oferta en streaming de talleres, charlas y sesiones de mentoría a los estudiantes.

- Una visita educativa a través del formato inmersivo mediante la reserva, a horas concertadas, de una sesión con el equipo educativo que permita avanzar.

Concluimos que la sociedad ha cambiado, el usuario ha cambiado. El cliente-visitanteusuario-espectador es hoy una persona más conectada, más social, más móvil, es multipantalla, está hiperinformada, es más crítica, más exigente, más impaciente, más participativa y espera atención e información en tiempo real. Nuestra oferta de servicios y contenidos debe estar en consonancia con ello. Es un reto difícil ya que los usuarios están acostumbrados a recibir un muy buen servicio de agentes como Amazon, Booking, Netflix, etc., por lo que sus expectativas son crecientes.

Las nueve emociones positivas identificadas en una experiencia interesante en los museos pueden ser extrapolables a las experiencias virtuales. Estas nueve emociones son: anticipación, fascinación, inspiración, encanto, diversión, sorpresa, orgullo, alegría y satisfacción. Saber responder a estas expectativas emocionales dará como resultado una experiencia de usuario óptima, pero para ello será necesario diseñar y programar una oferta orientada a satisfacer las expectativas y necesidades de cada usuario.

Somos conscientes también de que otra palabra clave que debemos retener es percepción, porque lo que cuenta no es cómo la organización se presenta, planifica y considera lo que hace, sino cómo la perciben sus usuarios, qué impresión se llevan, cómo es su experiencia. Esto es lo que definirá su comportamiento futuro respecto a la organización, si repetirá (fidelización), la recomendará a amigos y familiares, emitirá una opinión favorable en sus redes o, por el contrario, no volverá nunca o, peor aún, difundirá su mala experiencia en su entorno y sus redes. Como museo, debe preocuparnos, además, si estamos ofreciendo un servicio adecuado a nuestro público, si estamos cumpliendo con nuestra misión cultural y social. 


\section{Referencias}

BLISS, J. (2018). Podcast Customer Experience. <https://ww.customerbliss.com/the-chiefcustomer-officer-human-duct-tape-show/>[Consulta: 15 de enero de 2021].

FERRAN, N. et al. (junio 2018). Marc, Maria y David: el diseño de experiencia de usuario $(U X)$ aplicado a la biblioteca pública. BiD: textos universitaris de biblioteconomia $\mathrm{i}$ documentació (n. $\left.{ }^{\circ} 40\right)$. $<$ http://bid.ub.edu/es/40/ferran.htm>[Consulta: 21 de enero de 2021].

LÓPEZ, L (2016). Aplicaciones multidisciplinares de las TIC desde la Universidad de Deusto. Recuperado de <https://blogs.deusto.es/aplicaciones-tic/la-realidad-aumentaday-la-educacion/> [Consulta: 15 de febrero de 2021].

LÓPEZ, M (2014). Realidad aumentada en la educación. Recuperado de $<\mathrm{https}$ ://www.nubemia.com/realidad-aumentada-en-la-educacion/>

RODÀ, C. (2010). "De 1.0 a 2.0: el viaje de los museos a la comunicación social", Revista $m u s-A, 12,2010$, pp. 22-33

RODÀ, C (2020). "Digital a museus, ara més que mai", NÚVOL, monogràfic de museus, mayo 2020.

RODÀ, C. (2013). "El Museo como Conector", Revista de Museología, 56.

RODÀ, C. (2004). "La comunicación multicanal: Canal Cultura", Revista de Patrimonio Andaluz.

RODÀ, C. (2012). "La hora 2.0 del Museu Picasso de Barcelona", Revista digital ICOM España, 5, pp. 11-18.

RODÅ, C (2017). Visitor Journey Mapping: ponernos en la piel del visitante. $<$ http://blog.museunacional.cat/es/visitor-journey-mapping-ponernos-en-la-piel-delvisitante/> [Consulta: 1 de febrero de 2021].

VILLAESPESA, E. (2013). "El museo en la web social y su impacto en los visitantes", Revista Museología (n. ${ }^{\circ}$ 56, julio de 2013).

VILLAESPESA, E. (2014). Understanding people's motivation and usage of the Tate online collection. Tate. 